\title{
Trigger mechanisms in insulin resistance and diabetes mellitus development
}

\author{
Vira Zlatkina', Olena Karaya ${ }^{2}$, Natalia Yarmish ${ }^{3}$, Anna Shalimova ${ }^{4}$ \\ 'Department of Clinical Pharmacy and Internal Medicine, Kharkiv National Medical University, Kharkiv 61022, Ukraine. \\ ${ }^{2}$ Department of General Practice - Family Medicine, Kharkiv National Medical University, Kharkiv 61022, Ukraine. \\ ${ }^{3}$ Department of Biochemistry, Kharkiv National Medical University, Kharkiv 61022, Ukraine. \\ ${ }^{4}$ The Government Institution "L.T. Malaya Therapy National Institute of the National Academy of Medical Sciences of Ukraine", \\ Kharkiv 61039, Ukraine.
}

Correspondence to: Dr. Anna Shalimova, The Government Institution "L.T. Malaya Therapy National Institute of the National Academy of Medical Sciences of Ukraine", Kharkiv 61039, Ukraine. E-mail: anna.shalimova83@gmail.com

How to cite this article: Zlatkina V, Karaya O, Yarmish N, Shalimova A. Trigger mechanisms in insulin resistance and diabetes mellitus development. Vessel Plus 2019;3:7. http://dx.doi.org/10.20517/2574-1209.2019.03

Received: 21 Dec 2018 First Decision: 22 Jan 2019 Revised: 25 Jan 2019 Accepted: 26 Jan 2019 Published: 19 Mar 2019

Science Editor: Alexander N. Orekhov Copy Editor: Cai-Hong Wang Production Editor: Huan-Liang Wu

\begin{abstract}
Type 2 diabetes mellitus characterized by chronic hyperglycaemia is caused by insulin resistance and $\beta$-cell dysfunction. Glycogen accumulation, due to impaired metabolism, contributes to this "glucotoxicity" via dysregulated biochemical pathways promoting $\beta$-cell dysfunction. Thus, long-term exposition of insulin-secreted cells or isolated islets together with increased free fatty acids (FFA) and glucose levels can cause insulin-induced glucose secretion depression, damage to insulin gene expression and apoptotic death of cells. It is known that, the main regulator of pancreatic $\beta$-cells functioning and regulator of insulin gene expression, synthesis and secretion of insulin is glucose. Glucose enters cells and progressively metabolizes, in particular, to pyruvate in a cycle of tricarboxylic acids, subjected to oxidative phosphorylation, during which formed adenosine triphosphate and reactive oxygen radicals (ROS). Although, when more glucose enters the cell, there are other ways in which extra glucose can be transferred to reserve and of the glucose molecules can form ROS. The release of excessive amounts of FFA leads to lipotoxicity, as lipids and metabolites produce ROS in the endoplasmic reticulum and mitochondria. This affects both adipose and non-fat tissue, making up its pathophysiology in many organs. This overview demonstrates that the insulin gene is expressed in pancreatic $\beta$-cells. Glucose is the main physiological regulator of insulin gene expression. It controls the effect of transcription factors, insulin mRNA stability, and transcription rate. Glucolipotoxicity mechanisms affect the transcription factors MafA and PDX-1. Important is the $\beta$-cells damaging, which is connected with the oxidative stress and the synthesis of ceramides.
\end{abstract}

Keywords: Diabetes mellitus, insulin resistance, glucotoxicity, lipotoxicity

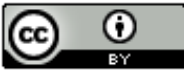

(C) The Author(s) 2019. Open Access This article is licensed under a Creative Commons Attribution 4.0 International License (https://creativecommons.org/licenses/by/4.0/), which permits unrestricted use, sharing, adaptation, distribution and reproduction in any medium or format, for any purpose, even commercially, as long as you give appropriate credit to the original author(s) and the source, provide a link to the Creative Commons license, and indicate if changes were made.

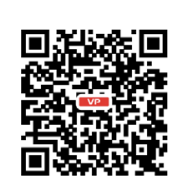




\section{INTRODUCTION}

Our narrative review summarizes the results of studies of trigger mechanisms (in particularly, glucotoxicity) in insulin resistance (IR) and type 2 diabetes mellitus (DM) development. When searching PubMed for the next keyword combination "insulin resistance and type 2 diabetes and mechanisms", we received 4,307 results (2,976 of them in the last 10 years). When narrowing the search with the keyword combination "insulin resistance and type 2 diabetes and glucotoxicity", we received 104 results (55 of them in the last 10 years). Mostly, the article presented literary sources limited to the search for the last 10 years (until now). Nevertheless, we included older publications (preferring high-ranking journals) in case of seminal studies or when few studies were available for a specific topic. Of the articles retained, we included 57 that were most specific to trigger mechanisms in IR and DM development.

Type $2 \mathrm{DM}$ is a progressive chronic disease characterized by chronic hyperglycemia caused by IR and $\beta$-cell dysfunction ${ }^{[1]}$. Pancreatic $\beta$-cells play a fundamental role in the maintenance of glucose homeostasis in mammalians ${ }^{[2]}$. It is proved that by the time of type 2 DM development, sensitivity of peripheral tissues to insulin is reduced by $70 \%$, and insulin secretion - by $50 \%{ }^{[3]}$. The loss of insulin sensitivity in muscle, fat and liver tissues has the greatest clinical significance. Understanding of IR development mechanisms, search for genes responsible for its development is extremely important for the working out of new approaches to the treatment of type 2 DM. A study in the field of molecular biology has shown that patients with type 2 DM have genetic defects that are responsible for transmission of the signal after joining of insulin with the receptor (post-receptor defects) $^{[4]}$.

Insulin realizes the metabolic effect through the activation of phosphatidylinositol-3-kinase (PI3K) and protein kinase B (PKB, Akt). Serine/threonine kinase Akt phosphorylates GSK3 $\beta$ and FOXOs transcription factors that directly or indirectly mediate the effect of insulin on transcription of genes involved in carbohydrate metabolism. The deletion or deactivation of the genes Akt1 and Akt2 blocks the effect of insulin on glucose metabolism ${ }^{[5,6]}$.

Through PI3K and phosphorylation of proto-oncogene Cbl, activates glucose transporter 4 (Glut 4$)^{[7]}$. Thus, the biological effect of insulin is associated with the activation of glucose uptake by adipocytes and myocytes (Glut4), activation of glycogen synthesis (glycogen synthase) and protein (S6-kinase). Insulin regulates transcription of more than 150 genes. There are 7 groups of insulin-regulated sequences or elements (IRS/ IRE $)^{[8]}$, including sterol-regulated element-binding protein 1c (SREBP-1c). SREBPs are transcription factors of the helix-loop-helix (bHLH) family in the liver. Forms SREBP-1a, SREBP-1c and SREBP-2 affect the homeostasis of cholesterol and lipids. Srebp-1c expression is regulated by insulin regardless of glucose level [Figure 1] ${ }^{[9]}$.

Hyperexpression of dominant negative forms of SREBP-1c prevents induction of hepatic pyruvate kinase, spot 14 and fatty acid synthase mediated by insulin ${ }^{[10]}$. The expression of glucokinase (GK) in the liver is regulated by insulin, regardless of the level of glycemia.

Insulin also causes repression through removal from the core and acceleration of the degradation of a FOXO transcription positive regulator. In $\beta$-cells, the FOXO1 nuclear factor is a repressor of the positive activity of the nuclear transcription factor $\mathrm{Hnf} 3 \beta$ (FOXO2) in the PDX1 promoter, while insulin increases repression through deletion of FOXO1 from the nucleus.

The highly conservative area, located $340 \mathrm{bp}$ upstream of the start of transcription initiation, subsequently renamed as a promoter of insulin, controls the production of insulin by tissues and the regulation of the insulin gene itself. Most factors act here, which determine high transcription, these include cis-regulatory 


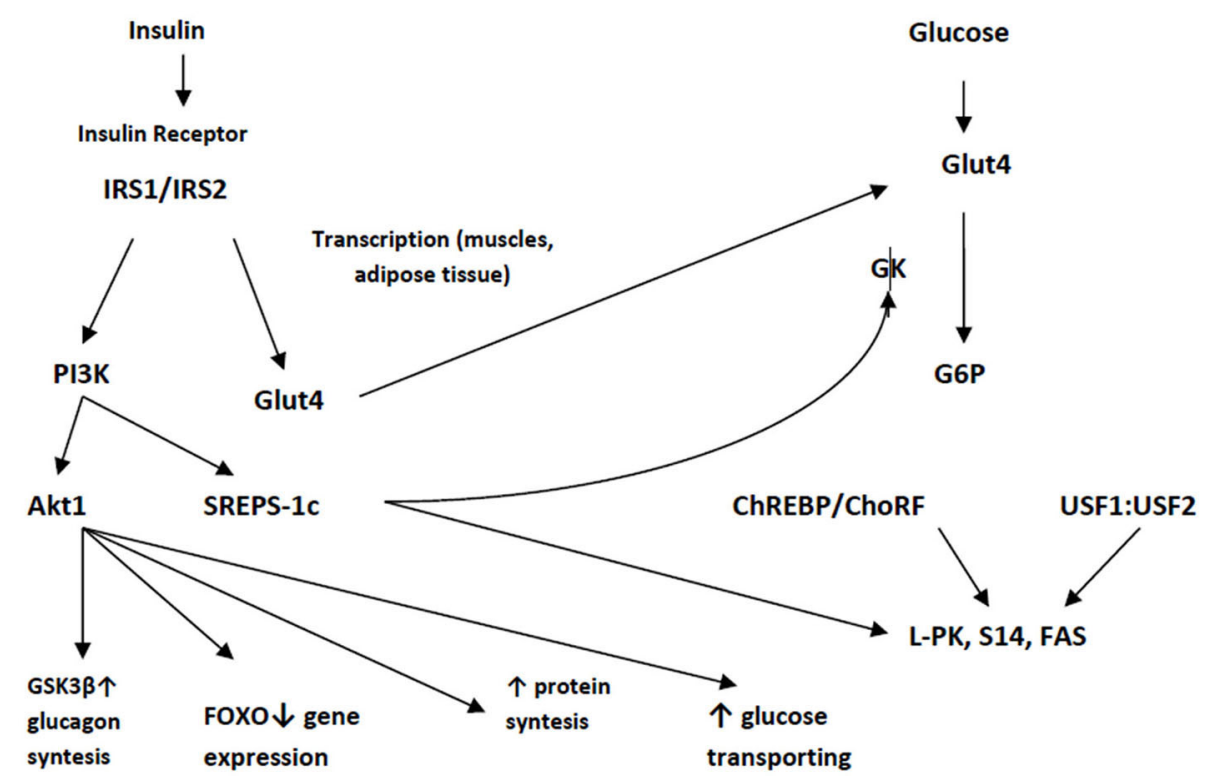

Figure 1. The effect of insulin and glucose on the regulation of gene expression ${ }^{[9]}$. IRS1/IRS2: insulin receptor substrates 1 and 2; Akt1: proteinase B; PI3K: phosphatidylinositol-3-kinase; SREBP-1c: sterol-regulated element-binding protein 1C; FAS: fatty acid synthase; FOXO: transcription factors; Glut4: glucose transporter; GK: glucokinase; L-PK: liver pyruvate kinase; S14: spot 14; G6P: glucose-6-phosphate

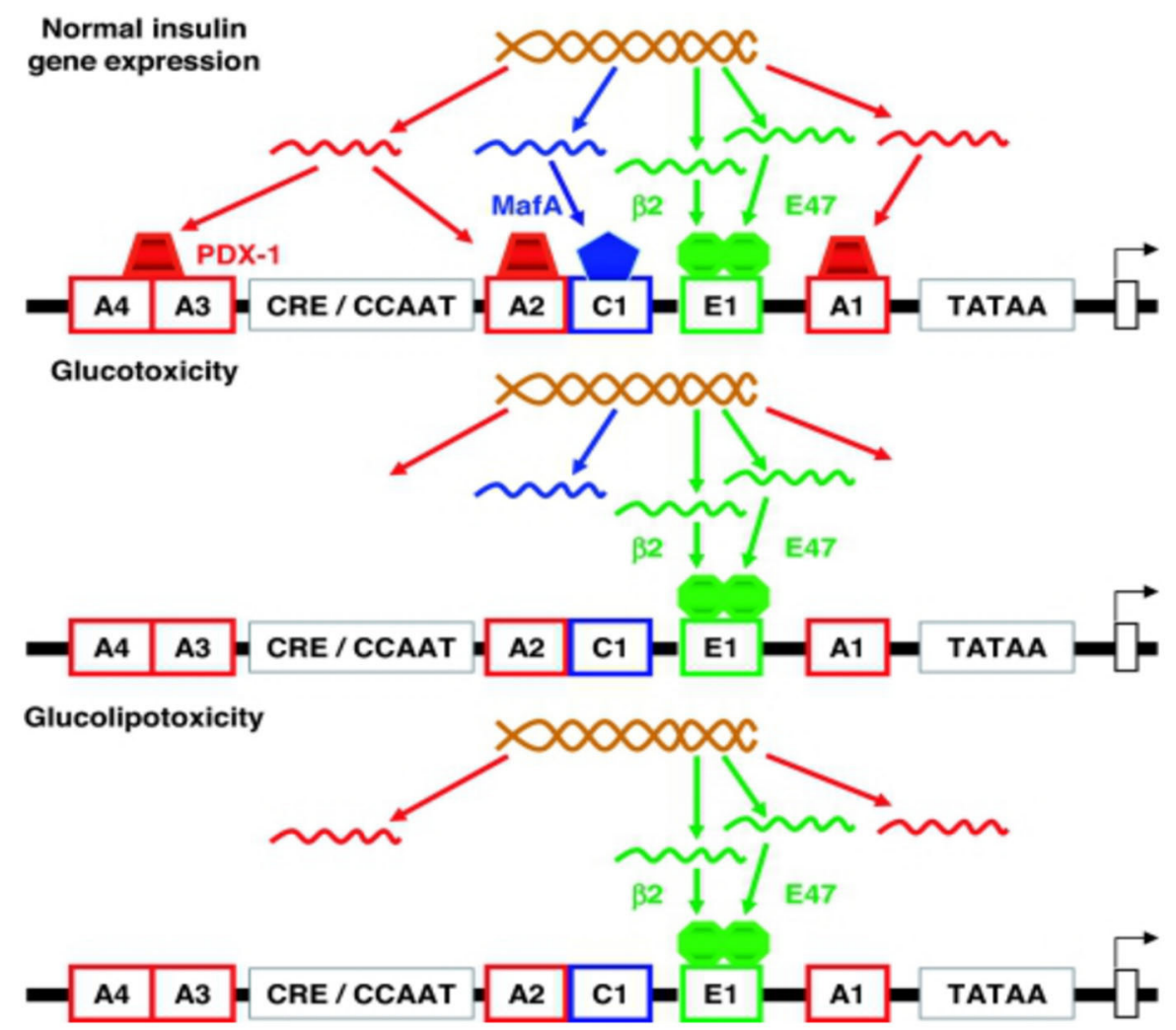

Figure 2. Schematic representation of the proximal area of the insulin 2 promoter in rats ${ }^{[11]}$. C1 (RIRE3b1): promoter node; BETA2 (NeuroD): transcription factor; PDX-1 (IDX-1/STF-1/IPF1): pancreatic/duodenal homeobox-1

elements, which are involved into activation in vitro [Figure 2].

Insulin promoter factor (PDX-1) also works with proteins of the basic dimerization transcription factors 
(bHLH), binded with box E ${ }^{[12]}$. Activator E1 is a dimer consisting of two polypeptide chains. The interaction between the dimerization transcription factors (bHLH) and the insulin promoter factor (PDX-1), includes other coactivators and DNA-binding proteins, for example, MafA, co-promoter $\mathrm{C}^{[13]}$. MafA controls the expression of $\beta$-cells, a specific expression of the insulin gene through a cis-regulatory element called RIPE3b1, and function as a powerful transactivator of the insulin gene ${ }^{[13,14]}$. While PDX-1 and NeuroD are expressed in different types of islet cells, MafA is a specific transactivator of the insulin gene only in $\beta$-cells. Therefore, the power of MafA as an activator of the insulin gene, together with the unique expression in $\beta$-cells, increases the probability that MafA is the main factor in the formation and function of these cells ${ }^{[15]}$.

The deterioration of $\beta$-cells may result from a combination of genetic and environmental factors. Hyperglycemia, even moderate, observed before the development of diabetes, can lead to damage to $\beta$-cells through a process known as "glucotoxicity". The second phenomenon, lipotoxicity, also leads to $\beta$-cell damage ${ }^{[12]}$. Both of these processes can be considered as abnormal, because glucose and lipid levels are not toxic, but very important for normal functioning of $\beta$-cells. Therefore, there is a range of variances from the normoglycemic and normolipidemia conditions to disturbed hyperglycemic and hyperlipidemia conditions. Unger and colleagues were the first to introduce the concept of "glucotoxicity" and "lipotoxicity" ${ }^{\text {,[16] }}$. In their first article, glucose toxicity means continuous super-stimulation of $\beta$-cell glucose, which ultimately leads to insulin stores exhaustion, aggravation of hyperglycemia and to final worsening of $\beta$-cells functioning. The hypothesis about the cause of $\beta$-cell functioning aggravation was based on the exposure of $\beta$-cells in conditions of excessive lipid levels. The recognition of glucolipotoxicity presence is based on changes in intracellular lipids, which form the basis of lipotoxicity mechanism and depend on elevated glucose levels. Thus, glucotoxicity and lipotoxicity are correlated and have the same mechanisms ${ }^{[17]}$.

\section{GLUCOTOXICITY}

Glycogen accumulation, due to impaired metabolism, contributes to this "glucotoxicity" via dysregulated biochemical pathways promoting $\beta$-cell dysfunction ${ }^{[18]}$.

In general, some studies in vitro, tried to find glucolipotoxicity mechanisms formation, using isolated Langerhans islets and $\beta$-cells in pancreatic tissue. Long-term exposition of insulin-secreted cells or isolated islets together with increased free fatty acids (FFA) levels and glucose can cause insulin-induced glucose secretion depression, damage to insulin gene expression and apoptotic death of cells ${ }^{[11]}$.

The increase of IR and defeat of $\beta$-cells are the basis of type 2 DM progression and these two factors have different values and degrees of change. IR provokes changes that occur before the onset of hyperglycemia, and reaches its maximum values at relatively early stages of disease progression. Data extrapolated from UKPDS and Belfast Diet Study suggests that $\beta$-cell dysfunction precedes the development of diabetes for up to 15 years. In addition, the UKPDS showed a correlation between long-term, gradual deterioration of glycemic control and progressive dysfunction of $\beta$-cells, confirming the view that the defeat of these cells may be the leading factor in the disease ${ }^{[19,20]}$.

Studies, which are currently being conducted, show that disorders on the part of $\beta$-cells are not only in an insulin secretion depression. They are multi-factorial and involve a lot of defects, in particular: alternation in the ability of $\beta$-cells to respond the stimulation of glucose (change I phase of insulin secretion), violation of insulin formation (proinsulin/insulin ratio), changes in $\beta$-cell mass.

The main regulator of pancreatic $\beta$-cells functioning and regulator of insulin gene expression, synthesis and secretion of insulin is glucose. Due to glucose action, all the stages of insulin release (transcription, slicing of pre-RNA, stability of mRNA) are made. In this case, the main elements that regulate the transcription of the insulin gene are C1, E1, A3 [Figure 2]. In addition, the peripheral glucose sensitive element binds 
glucose-sensitive cells that take place in the islets of Langerhans. Glucose increases the connecting of PDX1 with node $\mathrm{A} 3^{[21]}$ and affects the transactivating of PDX-1 ability. Furthermore, insulin gene transcription stimulation of PDX-1 involves co-activators, like p300, which can change the structure of chromatin through posttranslational histones modification (methylation and/or acetylation) ${ }^{[22]}$.

At the moment, it's been examined in detail but still controversy regarding the mechanisms by which glucose transduction contributes to enhancing the binding of the insulin promoter and PDX-1. PDX-1 probably experiences multiple posttranslational modifications, possibly by $O$-binding $N$-acetylglucosamine ${ }^{[23]}$, or a small modifier $1^{[24]}$. A number of kinases have been suggested for phosphorylation of intermediate PDX-1, including mitogen-activated protein kinase (MARK) and $\mathrm{PI} 3 \mathrm{~K}^{[25]}$.

Regardless of insulin, glucose regulates the expression of genes responsible for carbohydrate metabolism. G6P, xylitol or hexosamine synthesis intermediates can be signal molecules in these processes. The study of the role of glucose is hampered by the influence of insulin [Figure 1]. First, the entry of glucose into the myocytes and adipocytes is carried out as a result of translocation Glut4. Secondly, GK activity is transcriptionally regulated by glucose and insulin in the liver and pancreas.

Most of the earliest works showed paradoxical glucose ability to reduce the function of $\beta$-cells. Using the HIT-T15 cell line and levels of glucose ( 0.8 or $11.1 \mathrm{mmol} / \mathrm{L}$ ), long-term cell cultivation in RPMI 1640 medium was observed to lead to low glucose concentrations, levels of insulin mRNA, which proved the fact that high glucose concentrations cause glucotoxisity action on pancreatic $\beta$-cells. When incubation lasted for 5 or 10 weeks after the occurrence of glucotoxic effects, the function of $\beta$-cells was reversible ${ }^{[26]}$. Hit-T15 cells have been cultivated for a long period in an environment with a glucose concentration of 0.8 or $11.1 \mathrm{mmol} / \mathrm{L}$ with and without somatostatin, an inhibitor of insulin secretion. Cells cultured with somatostatin had critically low insulin levels in culture media, demonstrating the rest of $\beta$-cells. Cells exposed to high glucose and somatostatin showed glucotoxic effect on insulin gene expression, insulin secretion content and stimulation, depletion of $\beta$-cells.

Experiments on the line of $\beta$-cells, $\beta$-TC-6, also associated with HIT-T15 cells that are produced at high and low glucose concentrations, have demonstrated that it is the reduction of MafA that leads to a decrease in insulin gene expression in the presence of glucotoxicity, rather than the binding of insulin promoter factor 1 (PDX-1) and DNA.

In this case, it is important to note that these factors (PDX-1, MafA, etc.) do not work independently, but with each other, while activating transcription of insulin ${ }^{[13]}$. The effect of cells that secrete insulin on the background of an elevated glucose levels for less than a month reduces the expression of the insulin gene is associated with a decrease in MafA and PDX-1 binding activity ${ }^{\left[{ }^{3}\right]}$. The decrease in PDX-1 binding activity involves post-transcriptional control ${ }^{[21]}$, although the exact mechanisms remain unclear. In vivo PDX-1 expression was also reduced in partially pancreatectomized hyperglycemic rats ${ }^{[27]}$ and in diabetic gerbils Psammomysobesus ${ }^{[28]}$ and its binding activity was decreased in islets in Zucker rats with obesity and diabetes $^{[29]}$. With glucotoxicity, the binding activity of MafA in insulin-producing cells decreases ${ }^{[21]}$.

It is obvious that glucotoxicity may be associated with oxidative stress (OS). In the early studies it was reported that antioxidants $\mathrm{N}$-acetylcysteine and aminoguanidine protect HIT-T15 and isolated islets from toxic action of long-term cultivation in environments with high concentrations of glucose ${ }^{[30]}$. It is known that $\beta$-cells, in contrast to other sources, contain a sufficiently low concentration of antioxidant enzymes. This confirms that $\beta$-cells are at risk for oxidative stress. In diabetic rats that received antioxidants, normalization of glucose concentrations occurs, insulin production is restored, and insulin mRNA levels are reduced ${ }^{[2]]}$. 
Glucose enters cells and progressively metabolizes, in particular, to pyruvate in a cycle of tricarboxylic acids, subjected to oxidative phosphorylation, during which formed ATP and reactive oxygen radicals (ROS). There are other ways in which elevated glucose concentrations can be moved to the reserve, while ROS is formed from glucose ${ }^{[31]}$.

In an animal with diabetes, the binding of PDX-1 to DNA in HIT-T15 cells decreases, while this effect decreases with the use of antioxidants. Studies were conducted to clarify the place where the loss of PDX-1 occurs in the $\mathrm{OS}^{[13]}$. These results show that the OS induces the loss of PDX-1 post-transcriptional mRNA.

In the 1990s, separate groups measured OS markers at type 2 DM using various methods (high-performance liquid chromatography, mass spectrometry, immunocytochemistry). It has been shown that markers of OS are increased in subjects with type $2 \mathrm{DM}$, namely: the levels of 8-OH-guanine, 8-epi-PGF2 (prostaglandin F2), 4-OH-2-nonenal, hydroperoxides ${ }^{[13,32]}$. Yoshida et al ${ }^{[33]}$ reported that the appointment of antidiabetic drug at the half-year review led to a normalization of the activity of glutamylcysteine synthetase, glutathione and thiol transport.

\section{LIPOTOXICITY}

In case of dyslipidemia and obesity, the oversupply of fat to tissues not suited for lipid storage induces cellular dysfunction that underlies 2 type DM and coronary artery disease ${ }^{[34]}$. Disorders of lipid metabolism lead to the dysfunction of $\beta$-cells in patients with type $2 \mathrm{DM}^{[12]}$. It was shown that the influence on islets and $\beta$-cells with high concentrations of FFAs in vitro weakens the expression of the insulin gene at the same time with increased glucose concentration. Damaging action of FFAs on expression of insulin gene in isolated pancreatic islets is associated with high levels of triglycerides $(\mathrm{TG})^{[35,36]}$.

Since both palmitate and oleate inhibit insulin secretion, but only palmitate reduces the expression of the insulin gene ${ }^{[37]}$, it is accepted without proof that these two functional effects are based on similar mechanisms. Scientists suggest that the inhibition of the expression of the insulin gene by palmitate may be due to the formation of ceramides. Ceramide - an intermediate in the biosynthesis of sphingomyelin is formed by the interaction of sphingosine with acyl-coenzyme-A. The most important role of ceramide is participation as a messenger in the signal path of sphingomyelin and in the regulation of cellular processes such as differentiation, proliferation and apoptosis.

Excess quantities of ceramide inhibit the path of insulin signal transduction by inhibiting phosphorylation of protein kinase Akt/PKB and inhibits the translocation of Akt/PKB from the cytoplasm to the plasma membrane, which then inactivates the path of transduction of the insulin signal. Indeed, in obese people suffering from IR, levels of ceramide in skeletal muscles are increased by 2 times. This increase is due to the high concentrations of free fatty acids in plasma and a decrease in the intensity of phosphorylation of protein kinase $\mathrm{Akt}^{[38]}$.

In connection with the decrease in the binding of MafA and PDX-1 is the inhibition of transcription of the insulin gene by palmitate [Figure 3] ${ }^{[13,39]}$. Interestingly, in contrast to glucotoxicity mechanisms that include various types of $\mathrm{MafA}^{[39]}$, the ways by which the formation of ceramide from palmitate dicrease PDX-1 concentration and the expression of MafA are unknown. Two main ways of signaling are modulated by ceramides, MAPK and PI3K regulate the transcription of the insulin gene with impact on the activity of the transcription factor. The form of C-jun N-terminal kinase (JNK) is a direct target for ceramide in many cell systems. In $\beta$-cells, JNK inhibits transcription of insulin gene and via C-jun-dependent transcription inhibition of $\mathrm{E} 1^{[40]}$ and $\mathrm{C}$-jun-independent binding inhibition PDX-1 [Figure 3] ${ }^{[41]}$.

To prove that increased levels of ceramide lead to glucose homeostasis disorders, experiments with animals and pharmacological agents were carried out. Indeed, the reduction of ceramide levels (by inhibiting its 


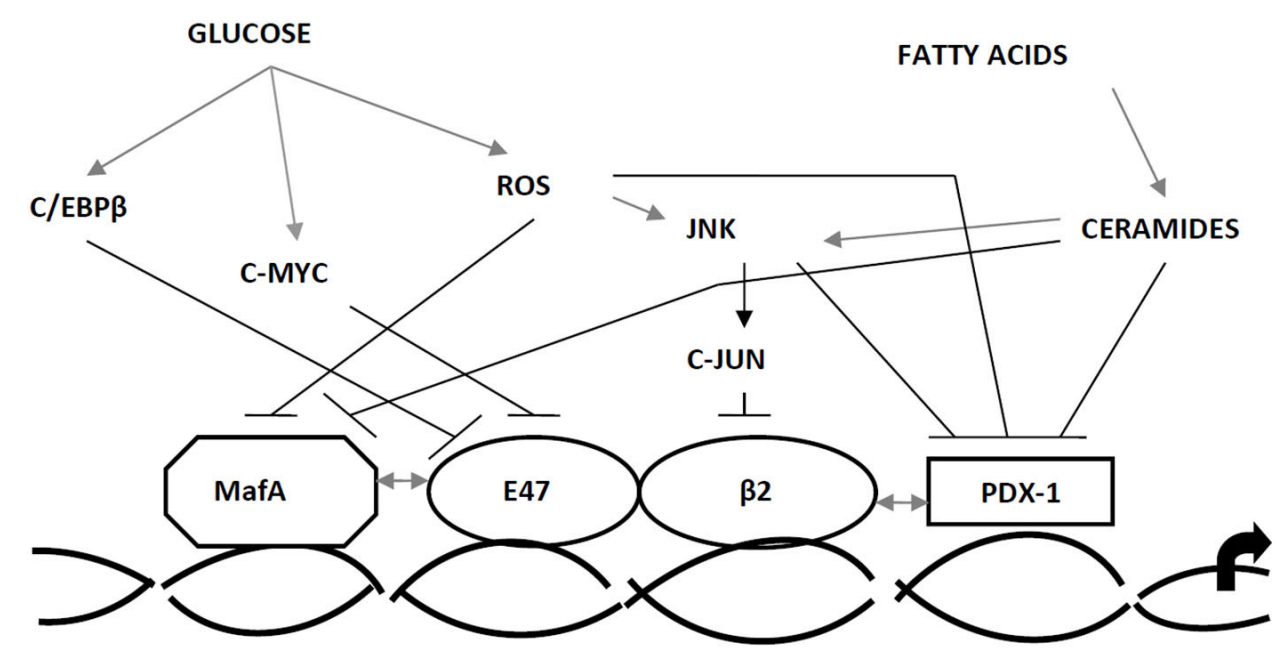

Figure 3. Intracellular mechanisms of insulin gene transcription damage by high concentrations of glucose and fatty acids[11]. ROS: reactive oxygen radicals; PDX-1: pancreatic/duodenal homeobox-1; C/EBP $\beta$ : CCAAT/enhancer binding protein $\beta$; JNK: C-jun N-terminal kinase

synthesis) improves glucose homeostasis in insulin-resistant transgenic mice with obesity and diabetes ${ }^{[42]}$.

Thus, PDX-1 and MafA are main targets of gluco- and lipotoxic processes, they operate in other ways. Glucotoxicity is connected with a decrease in the expression of MafA and PDX-1 proteins, whereas in the conditions of PDX-1 lipotoxicity it is expressed, but retained in the cytosol, the levels of MafA mRNA are reduced.

At IR, the level of FFA in hepatocytes increases, because in these cells: (1) lipogenesis de novo increases; (2) esterification of free fatty acids exceeds their oxidation; (3) esterified free fatty acids are stored in the form of triglycerides or sent to the synthesis of cholesterol lipoproteins of very low density (VLDL); (4) insulinregulated mobilization of triglycerides decreases.

Insulin-resistant adipocytes intensely break down the triglycerides contained in them and release the formed of them into the bloodstream. The flow of FFA from fat cells increases and FFA also comes out of VLDL and chylomicrons from plasma and blood partially go to other organs, and partially - back to the liver where they are again transformed into TG. A certain "pumping" of the liver by FFA and triglycerides takes place. This has the most serious consequences.

Prolonged exposure of $\beta$-cells with fatty acids in vitro increases the main insulin release and inhibits glucose-stimulated insulin secretion ${ }^{[43]}$, a phenomenon observed in vivo in rats ${ }^{[4,45]}$. These two effects have different time intervals and are likely to have separate mechanisms. Citrate-synthase activity decreases in the presence of fatty acids in the islets cultivated within 24 hours, causing a decrease in citrate levels and an increase in phosphofructokinase activity ${ }^{[46]}$. This, in turn, reduces the levels of G6P, disinhibits GK and increases the utilization of glucose at low concentrations of glucose. In vivo, FFA also reduces the response of the sympathetic nervous system, so insulin secretion increases ${ }^{[47]}$.

Particular attention should be paid to the separating protein-2 (UCP-2), a mitochondrial transporter that splits the respiratory chain at the ATP synthesis stage ${ }^{[48]}$, although its biological functions are still unclear. UCP-2 is assumed to modulate secretion of hormone insulin and to enact in glucolipotoxicity formation. On one hand, the increasing expression of UCP-2 - in $\beta$-cells weakens the secretion of insulin. On the other, UCP-2 elevates insulin concentrations in animals and protects against diabetes ${ }^{[48,49]}$. Third, UCP-2 expression 
is increased in islets after high-calorie feeding in rodents or after exposure with fatty acids in vitro ${ }^{[50]}$. Fourthly, oleic acid activates UCP-2 promoter in INS-1 cells, the effect mediating directly SREBP $1 c^{[51]}$ and indirectly by peroxisome proliferation activator receptor ${ }^{\left[{ }^{2}\right]}$. These observations confirm that the FFA stimulates the UCP-2 expressions in $\beta$-cells, possibly causing by dissociation of mitochondria.

Thus, the expression of UCP-2 levels in return to FFA can be a cellular ways of protection from overabundance of energy-containing components and OS. Harmful FFA action on the function of $\beta$-cells occurs if only glucose levels are increased. Prentki et al. ${ }^{[17]}$ assumed that glucose was the main determinant of FFA in $\beta$-cells. When the glucose concentration is not elevated, the FFA are transported via carnitinepalmityl-transferase-1 (CPT-1) to the mitochondria. When the concentrations of both glucose and FFA increase, the cycle of tricarboxylic acids generates signals that promote the formation of malonyl-CoA in the cytosol. Its role is to inhibit CPT-1, thus blocking the oxidation of fatty acids and, as a consequence, the accumulation of acetyl-CoA in the cytosol ${ }^{[11,17]}$. In addition, the accumulation of long-chain acyl-CoA in the cytosol, possibly directly, or by generating lipid-stimulating signals, either directly or through the generation of lipid-forming signals, can affect pancreatic $\beta$-cells ${ }^{[11]}$. Among the metabolic effects that guide the splitting of FFA to formation, glucose stimulates the gene expression which is taken partly in lipogenesis ${ }^{[53]}$. There is an enzyme - AMP-activated protein kinase (AMPK), which works as a metabolic sensor, and during an over-nutrition feeds signal to the $\beta$-cells to go into the "storage state" ${ }^{\text {n[5] }}$. AMPK activity inversely correlates with levels of glucose and is expressed with the help of palmitate ${ }^{[55]}$ in pancreatic $\beta$-cells. The SREBP1c transcription factor acts as an stimulator, transmitting the signal received by AMPK about changes in the expression of gene, which leads to an increase of lipids formation. It is known that glucose is able to stimulate the production of the $\mathrm{X}$ liver receptor, which is able to stimulate the production of SREBP1c and hyperlipidemia ${ }^{[5]}$.

The release of excessive amounts of FFA leads to lipotoxicity, as lipids and their metabolites produce OS in the endoplasmic network and mitochondria. This affects both adipose and non-fat tissue, making up its pathophysiology in such organs like liver and pancreas ${ }^{[12]}$. FFA released from excessive triglycerides deposits also inhibit lipogenesis, breaking a sufficient clearance triglyceride levels. The release of FFA under the action of endothelial lipoprotein lipase from increased serological triglycerides within the limits of increased $\beta$-lipoproteins causes lipotoxicity, which leads to insulin receptor dysfunction. Long-term insulin-resistant state creates hyperglycemia with compensated hepatic gluconeogenesis. The latter increases hepatic glucose production, further exacerbating hyperglycemia caused by insulin resistance. FFA also reduce the utilization of insulin-stimulated glucose in the muscles. Lipotoxicity from excessive amounts of FFA also reduces insulin secretion by pancreatic $\beta$-cells, which ultimately leads to the depletion of these cells ${ }^{[56]}$.

Therefore, the constant high glucose directs the fatty acids to cellular lipid synthesis. More recently, studies have shown that the metabolism of lipids and their transport are also involved in the mechanism of glucolipotoxicity.

In in vitro studies, important information regarding the molecular and cellular bases of glucolipotoxicity has been provided. Various functional results of chronically elevated levels of FFA are mediated by clear mechanisms and some of in vitro observations have been reproduced in vivo on rodent models.

\section{CONCLUSION}

Thus, the insulin gene is expressed in pancreatic $\beta$-cells. The main physiological regulator of the expression of insulin gene is glucose. It controls the effect of transcription factors, insulin mRNA stability, and transcription rate. Deterioration of the function of $\beta$-cells causes increased levels of glucose and lipids (glucolipotoxicity) at type 2 DM. Glucolipotoxicity mechanisms affect the transcription factors MafA and PDX-1. The OS and the synthesis of ceramides have important damages to the value of the $\beta$-cells. Reducing glucose levels is a key factor in the treatment of type $2 \mathrm{DM}$, preventing macro- and microvascular 
complications, while taking into account existing pathological effects that can affect pancreatic $\beta$-cells ${ }^{[57]}$.

\section{DECLARATIONS}

\section{Authors' contributions}

Study design, manuscript review: Zlatkina V, Karaya O, Yarmish N, Shalimova A

Development of methodology: Zlatkina V

Collection of data, analysis and/or interpretation of data, writing (not revising) all or sections of the manuscript: Zlatkina V, Karaya O, Yarmish N, Shalimova A

Supervision: Shalimova A

\section{Availability of data and materials}

Not applicable.

\section{Financial support and sponsorship}

None.

\section{Conflicts of interest}

All authors declared that there are no conflicts of interest.

\section{Ethical approval and consent to participate}

Not applicable.

\section{Consent for publication}

Not applicable.

\section{Copyright}

(c) The Author(s) 2019.

\section{REFERENCES}

1. Hall E, Dekker Nitert M, Volkov P, Malmgren S, Mulder H, et al. The effects of high glucose exposure on global gene expression and DNA methylation in human pancreatic islets. Mol Cell Endocrinol 2018;472:57-67.

2. Bensellam M, Jonas JC, Laybutt DR. Mechanisms of $\beta$-cell dedifferentiation in diabetes: recent findings and future research directions $\mathrm{J}$ Endocrinol 2018;236:R109-43.

3. Robertson RP, Harmon JS, Tanaka Y. Glucose toxicity of the $\beta$-cell: cellular and molecular mechanisms. In: Diabetes mellitus. A fundamental and clinical text. 2nd ed. In: Le Roith D, Taylor SI, Olefsky JM, editors. Philadelphia: Lippincott Williams \& Wilkins; 2000. pp. 125-32.

4. Staiger H, Machicao F, Fritsche A, Häring HU. Pathomechanisms of type 2 diabetes genes. Endocr Rev 2009;30:557-85.

5. Choe SS, Choi AH, Lee JW, Kim KH, Chung JJ, et al. Chronic activation of liver X receptor induces $\beta$-cell apoptosis through hyperactivation of lipogenesis: liver X receptor-mediated lipotoxicity in pancreatic $\beta$-cells. Diabetes 2007;56:1534-43.

6. Juntilla M, Wofford JA, Birnbaum MJ, Rathmell JC, Koretzky GA. Akt1 and Akt2 are required for alphabetathymocyte survival and differentiation. ProcNatlAcadSci U S A 2007;104:12105-10.

7. Huang JP, Huang SS, Deng JY, Hung LM. Impairment of insulin-stimulated Akt/GLUT4 signaling is associated with cardiac contractile dysfunction and aggravates I/R injury in STZ-diabetic rats. J Biomed Sci 2009;16:77.

8. Ide T, Shimano H, Yahagi N, Matsuzaka T, Nakakuki M, et al. SREBPs suppress IRS-2-mediated insulin signalling in the liver. Na Cell Biol 2004;6:351-7.

9. Pettinelli P, Del Pozo T, Araya J, Rodrigo R, Araya AV, et al. Enhancement in liver SREBP-1c/PPAR-alpha ratio and steatosis in obese patients: correlations with insulin resistance and n-3 long-chain polyunsaturated fatty acid depletion. BiochimBiophysActa 2009;1792:1080-6.

10. Huo M, Zang HL, Zhang DJ, Wang B, Wu J, et al. Role of increased activity of carbohydrate response element binding protein in excessive lipid accumulation in the liver of type 2 diabetic db/db mouse. Beijing Da Xue Xue Bao Yi Xue Bao 2009;41:307-12. (in Chinese)

11. Poitout V, Robertson RP. Glucolipotoxicity: fuel excess and $\beta$-cell dysfunction. Endocr Rev 2007;29:351-66. 
12. Ametov AS, Demidova TY, Tselikovskaya AL. Obesity and cardiovascular diseases. Therapeutic Archive 2001;73:66-9. (in Russian)

13. Kaneto H, Miyatsuka T, Shiraiwa T, Yamamoto K, Kato K, et al. Crucial role of PDX-1 in pancreas development, beta-cell differentiation, and induction of surrogate beta-cells. Cur Med Chem 2007;14:1745-52.

14. Nishimura W, Bonner-Weir S, Sharma A. Expression of MafA in pancreatic progenitors is detrimental for pancreatic development. Dev Biol 2009;333:108-20.

15. Artner I, Hang Y, Guo M, Gu G, Stein R. MafA is a dedicated activator of the insulin gene in vivo. J. Endocrinol 2008;198:271-9.

16. Unger RH. The physiology of cellular liporegulation. Annu Rev Physiol 2003;65:333-47.

17. Prentki M, Joly E, El-Assaad W, Roduit R. Malonyl-CoA signaling, lipid partitioning, and glucolipotoxicity: role in $\beta$-cell adaptation and failure in the etiology of diabetes. Diabetes 2002;51:S405-13.

18. Ashcroft FM, Rohm M, Clark A, Brereton MF. Is type 2 diabetes a glycogen storage disease of pancreatic $\beta$ cells? Cell Metab 2017;26:17-23.

19. Pelikánova T. Treatment of diabetes in metabolic syndrome. Vnitr Lek 2009;55:637-45.

20. Schatz H. 2008--The year of the big studies about the therapy of type-2-diabetes. ACCORD, ADVANCE, VADT, and the UKPDS 10year follow-up data. MMW Fortschr Med 2009;151:42-3.

21. Burkhardt BR, Cook JR, Young RA, Wolf BA. PDX-1 interaction and regulation of the Pancreatic Derived Factor (PANDER, FAM3B) promoter. Biochim Biophys Acta 2008;1779:645-51.

22. Stanojevic V, Habener JF, Thomas MK. Pancreas duodenum homeobox-1 transcriptional activation requires interactions with $\mathrm{p} 300$. Endocrinology 2004;145:2918-28.

23. Gao Y, Miyazaki J, Hart GW. The transcription factor PDX-1 is post-translationally modified by O-linked N-acetylglucosamine and this modification is correlated with its DNA binding activity and insulin secretion in min6 ß-cells. Arch Biochem Biophys 2003;415:155-63.

24. Kishi A, Nakamura T, Nishio Y, Maegawa H, Kashiwagi A. Sumoylation of Pdx1 is associated with its nuclear localization and insulin gene activation. Am J Physiol Endocrinol Metab 2003;284:E830-40.

25. da Silva Xavier G, Varadi A, Ainscow EK, Rutter GA. Regulation of gene expression by glucose in pancreatic ß-cells (MIN6) via insulin secretion and activation of phosphatidylinositol 3'-kinase. J Biol Chem 2000;275:36269-77.

26. Khoo S, Griffen SC, Xia Y, Baer RJ, German MS, et al. Regulation of insulin gene transcription by ERK1 and ERK2 in pancreatic $\beta$ cells. J Bio Chem 2003;278:32969-77.

27. Zangen DH, Bonner-Weir S, Lee CH, Latimer JB, Miller CP, et al. Reduced insulin, GLUT2, and IDX-1 in B-cells after partial pancreatectomy. Diabetes 1997;46:258-64.

28. Leibowitz G, Ferber S, Apelqvist A, Edlund H, Gross DJ, et al. IPF1/PDX1 deficiency and B-cell dysfunction in Psammomysobesus, an animal with type 2 diabetes. Diabetes 2001;50:1799-806.

29. Tanaka Y, Gleason CE, Tran PO, Harmon JS, Robertson RP. Prevention of glucose toxicity in HIT-T15 cells and Zucker diabetic fatty rats by antioxidants. Proc Natl Acad Sci U S A 1999;96:10857-62.

30. Tajiri Y, Moller C, Grill V. Long term effects of aminoguanidine on insulin release and biosynthesis: evidence that the formation of advanced glycosylation end products inhibits $\beta$-cell function. Endocrinology 1997;138:273-80.

31. Green K, Brand MD, Murphy MP. Prevention of mitochondrial oxidative damage as a therapeutic strategy in diabetes. Diabetes 2004;53:S110-8

32. Gopaul NK, Anggård EE, Mallet AI, Betteridge DJ, Wolff SP, et al. Plasma 8-epi-PGF2 levels are elevated in individuals with noninsulin dependent diabetes mellitus. FEBS Lett 1995;368:225-9.

33. Yoshida K, Hirokawa J, Tagami S, Kawakami Y, Urata Y, et al. Weakened cellular scavenging activity against oxidative stress in diabetes mellitus: regulation of glutathione synthesis and efflux. Diabetologia 1995;38:201-10.

34. Chaurasia B, Summers SA. Ceramides - lipotoxic inducers of metabolic disorders: (Trends in Endocrinology and Metabolism 26, 538550; 2015). Trends Endocrinol Metab 2018;29:66-7.

35. Hagman DK, Hays LB, Parazzoli SD, Poitout V. Palmitate inhibits insulin gene expression by altering PDX-1 nuclear localization and reducing MafA expression in isolated rat islets of Langerhans. J Biol Chem 2005;280:32413-8.

36. Briaud I, Harmon JS, Kelpe CL, Segu VB, Poitout V. Lipotoxicity of the pancreatic B-cell is associated with glucose-dependent esterification of fatty acids into neutral lipids. Diabetes 2001;50:315-21.

37. Gwiazda KS, Yang T, Lin Y, Johnson JD. Effects of palmitate on ER and cytosolic Ca2+ homeostasis in beta-cells. Am J Physiol Endocrinol Metab 2009;296:E690-701.

38. Widenmaier SB, Ao Z, Kim SJ, Warnock G, McIntosh CH. Suppression of p38 MAPK and JNK via Akt-mediated inhibition of apoptosis signal-regulating kinase 1 constitutes a core component of the beta-cell pro-survival effects of glucose-dependent insulinotropic polypeptide. J Biol Chem 2009;284:30372-82.

39. Kaneto H, Miyatsuka T, Shiraiwa T, Yamamoto K, Kato K, et al. Crucial role of PDX-1 in pancreas development, beta-cell differentiation, and induction of surrogate beta-cells. Curr Med Chem 2007;14:1745-52.

40. Vallerie SN, Furuhashi M, Fucho R, Hotamisligil GS. A predominant role for parenchymal c-Jun amino terminal kinase (JNK) in the regulation of systemic insulin sensitivity. PLoS One 2008;3:e3151.

41. Kawamori D, Kaneto H, Nakatani Y, Matsuoka TA, Matsuhisa M, et al. The forkhead transcription factor Foxo1 bridges the JNK pathway and the transcription factor PDX-1 through its intracellular translocation. J Biol Chem 2006;281:1091-8.

42. Weber C, Krueger A, Münk A, Bode C, Van Veldhoven PP, et al. Discontinued postnatal thymocyte development in sphingosine 1-phosphate-lyase-deficient mice. J Immunol 2009;183:4292-301. 
43. Zhou YP, Grill V. Long-term exposure to fatty acids and ketones inhibits $\beta$-cell functions in human pancreatic islets of Langerhans. J ClinEndocrinol. Metab 1995;80:1584-90.

44. Mason TM, Goh T, Tchipashvili V, Sandhu H, Gupta N, et al. Prolonged elevation of plasma free fatty acids desensitizes the insulin secretory response to glucose in vivo in rats. Diabetes 1999;48:524-30.

45. Paolisso G, Gambardella A, Amato L, Tortoriello R, D'Amore A, et al. Opposite effects of short- and long-term fatty acid infusion on insulin secretion in healthy subjects. Diabetologia 1995;38:1295-9.

46. Liu YQ, Tornheim K, Leahy JL. Fatty-acid induced $\beta$-cell hypersensitivity to glucose. Increased phosphofructokinase activity and lowered glucose-6-phosphate content. J Clin Invest 1998;101:1870-5.

47. Magnan C, Collins S, Berthault MF, Kassis N, Vincent M, et al. Lipid infusion lowers sympathetic nervous activity and leads to increased $\beta$-cell responsiveness to glucose. J Clin Invest 1999;103:413-9.

48. Zhang CY, Baffy G, Perret P, Krauss S, Peroni O, et al. Uncoupling protein-2 negatively regulates insulin secretion and is a major link between obesity, $\beta$-cell dysfunction, and type 2 diabetes. Cell 2001;105:745-55.

49. Joseph JW, Koshkin V, Zhang CY, Wang J, Lowell BB, et al. Uncoupling protein 2 knockout mice have enhanced insulin secretory capacity after a high-fat diet. Diabetes 2002;51:3211-9.

50. Lameloise N, Muzzin P, Prentki M, Assimacopoulos-Jeannet F. Uncoupling protein 2: a possible link between fatty acid excess and impaired glucose-induced insulin secretion? Diabetes 2001;50:803-9.

51. Medvedev AV, Robidoux J, Bai X, Cao W, Floering LM, et al. Regulation of the uncoupling protein-2 gene in INS-1 $\beta$-cells by oleic acid. J BiolChem 2002;277:42639-44.

52. Medvedev AV, Snedden SK, Raimbault S, Ricquier D, Collins S. Transcriptional regulation of the mouse uncoupling protein-2 gene. Double E-box motif is required for peroxisome proliferator-activated receptor- -dependent activation. J BiolChem 2001;276:10817-23.

53. Roche E, Farfari S, Witters LA, Assimacopoulos-Jeannet F, Thumelin S, et al. Long-term exposure of $\beta$-INS cells to high glucose concentrations increases anaplerosis, lipogenesis, andlipogenic gene expression. Diabetes 1998;47:1086-94.

54. Ruderman N, Prentki M. AMP kinase and malonyl-CoA: targets for therapy of the metabolic syndrome. Nat Rev Drug Discov 2004;3:340-51.

55. Wang X, Zhou L, Li G, Luo T, Gu Y, et al. Palmitate activates AMP-activated protein kinase and regulates insulin secretion from $\beta$ cells. Biochem Biophys Res Commun 2007;352:463-8.

56. Brøns C, Vaag A. Skeletal muscle lipotoxicity in insulin resistance and type 2 diabetes. J Physiol 2009;587:3977-8.

57. Dalle S. Diabetes: what are the key targets and the objectives? Preserving and protecting a functional pancreatic beta cell mass. Biol Aujourdhui 2017;211:165-8. (in French) 